\title{
RECENT WORK ON THE MEANING OF “LIFE'S MEANING”: SHOULD WE CHANGE THE PHILOSOPHICAL DISCOURSE?
}

\author{
THADDEUS METZ
}

\begin{abstract}
In this article I critically discuss English-speaking philosophical literature addressing the question of what it essentially means to speak of "life's meaning". Instead of considering what might in fact confer meaning on life, I make two claims about the more abstract, meta-ethical question of how to understand what by definition is involved in making that sort of enquiry. One of my claims is that over the past five years there has been a noticeable trend among philosophers to try to change our understanding of what talk of "life's meaning" connotes. For example, whereas most philosophers for a long while had held that such talk is about a kind of value possible in the life of human beings, recently some have argued that certain non-human parts of nature can exhibit meaningfulness, which, furthermore, is not necessarily something valuable. The second claim I advance is that there is strong reason to reject this trend, and instead for philosophers to retain the long-standing approach.
\end{abstract}

Key words: animal lives; concept of life's meaning; meaning of life; meaning of "meaning"; narrative; sense-making

\section{Introducing talk of "life's meaning"}

In this article I address the question of what it essentially means to speak of "life's meaning." When at least English-speaking philosophers use that phrase, what are they essentially connoting? Often this enquiry is framed in terms of what the concept of life's meaning is, where the concept includes those uncontested features common to contested conceptions of what might confer meaning on life. What are competing theories of life's meaning about, such that they are all about life's meaning as opposed to, say, happiness? Take the conceptions or theories that life is meaningful insofar as one fulfills a purpose God has assigned, receives one's just deserts in an afterlife, cultivates virtue in oneself, does what benefits others, or carries out one's reflective views of what is worthwhile. In virtue of what is it the case that these are rival views of life's meaning?

From about 40 years ago, when Robert Nozick (1981, pp. 571-613) published important work on the meaning of life, until recently, philosophers tended to overlap in their accounts of the concept of life's meaning. There were indeed a variety of analyses of it, e.g., in terms 
of: connecting with organic unity or at least intrinsic goods beyond oneself (Levy, 2005, pp. 178-180; Nozick, 1981, pp. 594-600); achieving certain purposes (Trisel, 2007); displaying narrative qualities in the shape of one's life (Wong, 2008); living in ways meriting reactions of esteem or admiration (Kauppinen, 2015); acting on reasons of love (Wolf, 2016); or a cluster of them all (Metz, 2013, pp. 24-35; Seachris, 2013). However, these accounts and those like them shared important common ground.

Specifically, these analyses at least implicitly accepted that talk of "life's meaning" is about: (A) human persons, and (B) centrally their voluntary choices that (C) exhibit a high final value that (D) is characteristically present in "the good, the true, and the beautiful" and (E) absent from the hypothetical lives of Sisyphus or of those in an Experience Machine. That is, nearly all maintained that the concept of life's meaning involves something about either individual human lives or the human race as a whole, with a focus on the decisions they could make, where those decisions are good for their own sake to a noteworthy degree, are typified by love/morality, wisdom/enquiry, and the arts/creativity, and are lacking in a life that either rolls a stone up a hill for eternity or is alone in a virtual reality device. Many thought we could say more than this, e.g., that the relevant value involves transcending limits or fulfilling purposes, but at least the above (A-E) features were relatively unquestioned.

In the past five years or so, this "standard view," as I shall call it here, is no longer taken for granted. In particular, conditions (A), (B), and (C) have been directly questioned, where questioning (C), that meaningfulness is a high final value, implies doubting (D) and (E). One aim of this article is to demonstrate how the literature has shifted in this manner, inviting us to change our understanding of the concept of life's meaning. For example, recently some revisionist philosophers have argued that certain non-human parts of nature can exhibit meaningfulness or that meaningfulness is not necessarily something valuable. Although there have been some recent, new analyses of the concept of life's meaning that implicitly accept the standard view (Martela, 2017; Visak, 2017), I set them aside in what follows, in order to focus on the works of revisionists who reject it.

A second claim I advance is that there is strong reason for philosophers to retain the long-standing analysis of the concept of life's meaning. It is not easy to make this case, since those who have proffered non-standard analyses have tended to be consistent, to note the implications of their views that others would find counterintuitive, and to "bite the bullet" in contending that their analyses merit acceptance. In what follows, I aim to provide some principled reasons for favoring the standard view, which often amount to the idea that conceptual analyses should clarify philosophical enquiry and facilitate debate among philosophers. ${ }^{1}$

I begin by addressing accounts of the meaning of "life's meaning" according to which non-human entities can exhibit meaningfulness. Then, I consider views that focus on human lives as bearers of meaningfulness but deny that choices are what precisely about those lives exhibit the meaning. Finally, I take up analyses of the concept that deny that meaningful human choices are always valuable. Although I do not suppose that I provide conclusive

\footnotetext{
1 I focus here on providing reasons to reject the non-standard views, lacking the space to evaluate the various arguments their advocates have put forth in support of them.
} 
reason to reject these revisionist views, I conclude that philosophers have some strong reason not to give up the standard view of the meaning of "life's meaning."

\section{Meaningfulness beyond humanness?}

The most radical departure from the standard view accords meaning to parts of nature that are non-human. One might suggest that this is not so radical, since under the heading of "life's meaning" philosophers have at times addressed why the universe exists. However, there is an important difference between, on the one hand, the classic questions of why there is something rather than nothing or why there is a physical world in its entirety, and, on the other, recent questions about the meaningfulness of certain non-human individuals within the physical world. The latter enquiries range from the putative meaningfulness of an animal's life to that of, well, a sandwich.

With regard to animals, philosophers have principally ${ }^{2}$ run with the intuition that there is a difference between a dog that sits around all day scratching itself and one that, say, is put into the service of human beings or looks after her pups. According to Duncan Purves and Nicolas Delon (2018), the latter sort of dog is at least conceptually capable of meaning insofar as she has intentions and acts on them in effortful ways that benefit others, regardless of whether doing good is the content of the intention. In contrast, according to Joshua Lewis Thomas (2018), it is the mere fact of benefiting others, regardless of whether purposeful agency was the cause, that is a logically possible contender for meaning.

Both views appear vulnerable to the criticism that they oddly imply that a logically possible source of meaning for a dog would be for it to do much good for others merely because it was forced to, on pain of getting whipped.

Presumably, though, advocates of the views could revise them to avoid this counterexample. It would be reasonable to add some kind of independence condition into the present analyses of the concept.

A critic might also be tempted to distinguish concepts of meaning according to their bearers, which, in turn are distinguished on a species basis. One might suggest that while animals are capable of meaning, it is of a sort distinct from that pertinent to human beings, because the two are different species.

Although I think this criticism is weak, the reason for thinking so turns out to ground a strong criticism of the view that the meaningfulness of animal lives is continuous with that of ours. Suppose that hypothetical shumans, beings that are like humans in every way except that they have pointy ears and cannot mate with us, were capable of the same kinds of meaning in their lives as us. Then, it would make little sense to suppose that the concept of meaning for them should be considered different from the concept that applies to us. If shumans were also capable of realizing the good, the true, and the beautiful, surely they would exhibit the same concept of meaningfulness that our lives could exhibit. Now, this explanation of why the same concept of meaning would apply to shumans and humans plausibly explains why it does not apply to both humans and animals. Even if animals are

2 For a different approach, see Mawson (2016, pp. 51-56). 
capable of influencing other beings in beneficial ways, that is all, in terms of overlap with us. Animals (or at least a very large majority of them) cannot, among a wide array of other things: love, where that involves a concept of another's self distinct from one's own; get an education; discover fundamental truths about themselves or their environment; compose poetry; appreciate music; tell jokes; do what it takes to become an Olympic athlete; avoid a repetitive existence; redeem bad parts of their lives by making good come from them; strive to have their lives end on a high note.

Here is a second major reason to deny that animals are conceptually capable of the sort of meaning that we are. When it comes to human persons, we normally find it apt to go out of our way to facilitate meaning in their lives for their sake. I act in ways that I believe will make the lives of my children and my students more meaningful, for example. I strive to cultivate empathy and sympathy on the part of my sons, so that they will have meaningful relationships as adults, while I aim to teach my pupils knowledge that is important as opposed to trivial. ${ }^{3}$ However, I doubt that many readers would act for the sake of meaning in an animal's life. If we act in ways expected to render an animal's life more "meaningful," it is instead for the sake of others expected to benefit thereby, for instance the humans that a dog serves or the pups that she raises. This difference in reason-giving suggests a difference in kind that should be captured with different analyses for philosophical purposes.

Based largely on these two considerations, I am currently inclined to suggest that a dog that acts in ways that benefit others can more plausibly be said to have an "impactful" life or to have "made a difference," which is distinct from living meaningfully (as per Nozick, 1989, pp. 162-180). However, if one wants to describe the lives of animals as "meaningful," I submit it should be deemed a sort that is not continuous with that conceptually ascribed to us.

More radical than the idea that animals are capable of meaning in their lives is the suggestion that inanimate objects or events can also exhibit meaning. That is one implication of the above mentioned view, from Thomas, that having beneficial consequences is sufficient for meaningfulness. For example, he accepts that an event such as "the fact that the force of gravity keeps us from floating off into space" has a "meaningful effect on our existence" (Thomas, 2018, p. 284; emphasis in original).

Another recent analysis of the concept of meaning entailing that non-living parts of nature can be meaningful has been advanced by Wim de Muijnck (2013). For him, talk of "meaningful" connotes whatever matters to (or could matter to) a sentient being, that is, whatever tends to elicit responses from an organism, and, in the case of a person, whatever she identifies with. This notion of meaningfulness is the idea of whatever prompts (or could prompt) a being to take a keen interest in its environment. Again, the willingness to bite the bullet is striking: "By my account, a sandwich is significant because it invites eating, and because eating can be a highly agent-relevant response-one can be very much involved in eating, and appetite is a core motive of any sentient animal" (de Muijnck, 2013, p. 1302).

\footnotetext{
3 I am not suggesting that striving to make a person's life meaningful for her sake means that it would be "good for" her in the sense of improving her well-being, something Thomas (2018, pp. 285-289). might suspect. Instead, one might act so as to enable someone meaningfully to sacrifice her well-being for a certain cause (e.g., Metz, 2016, pp. 24-26, 30-31).
} 
To be fair, neither the advocate of meaningful gravity nor that of meaningful sandwiches maintains that the sense in which these count as "meaningful" is the only sense that our lives can count (de Muijnck, 2013, pp. 1304-1305; Thomas, 2018, pp. 277-280). However, they do maintain that it is one central respect in which our lives count as "meaningful" that is continuous with other parts of the natural world. They posit their accounts as ways of capturing the meaningfulness of the good, the true, and the beautiful, either as having substantially beneficial effects on us, or occasions for us to be stimulated, respectively.

The reasons I gave for doubting that animal lives should be considered "meaningful" in the sense typically applied to our lives pertain with even greater force to the case of inanimate events and objects. Recall that one rationale was that the concept of life's meaning should constitute common ground among the various competing theories and views of what could substantively confer meaning on a being's existence, where the sorts of meaning of which a person and a sandwich are capable are quite divergent. The other rationale was that, whereas the sort of meaning of which a person is capable grounds a reason to act for her sake, it would be inappropriate to enhance the meaningfulness of gravity or a sandwich for their sake. Obtaining clarity about human meaning requires drawing distinctions.

\section{Human meaning beyond choices?}

For the rest of this article, let us restrict discussion to the lives of human persons (and whichever organisms might have relevantly similar capacities). The default position for the past few decades has been that it is by definition the case that a human being's choices principally bear the meaning in her life, with beneficence, knowledge, and creativity being exemplars (where the knowledge has taken some degree of will-power to acquire). However, in the past five years some philosophers have suggested that it is not merely choices that can bear meaning in a human's life, while others, much more boldly, have advanced positions implying that it is never choices that do.

For the weaker position, that decisions do not exhaust the facets of a human life that can be meaningful, some have maintained that babies and comatose human beings could conceivably have meaning in their lives. This sort of perspective follows from the analyses examined in the previous section; roughly, babies routinely matter to their parents or take an interest in the world (de Muijnck, 2013, p. 1295), while a permanently comatose individual could in principle benefit others simply by remaining alive (Thomas, 2018, pp. 281-282, 292). In addition, there is the suggestion from James Tartaglia (2015, esp. pp. 1-19), Timothy Mawson (2016, pp. 61-68), and others (e.g., Seachris, 2019; Thomas, 2019) that having been created for a certain reason could be meaning-conferring to some degree, as opposed to having emerged by chance. Here, the meaning is supposed to come from a source external to the one whose life is being deemed meaningful, say, from God's having created one for a purpose. Having been caused to exist in a certain way need not involve any action whatsoever on the part of the human being, not even electing to fulfill the assigned purpose.

Strictly speaking, these are not counterexamples to the standard view, according to which choices are "central" or "principal" bearers of meaning, leaving open the possibility that there are other facets of a life that could conceivably be bearers. So long as these 
non-volitional sources of meaning are peripheral, the standard view remains intact. Let us consider, therefore, rationales for the stronger position that indeed challenges the standard view. It is the claim that a person's actions are, logically speaking, never what exhibit meaning or fail to do so. Meaningfulness is never volitional, for some contemporary philosophers, but is instead always cognitive (or epistemic), where this is meant to be an analytic truth.

The purely cognitive approach largely springs from the hunch that there is continuity between the meaning of a life and the meaning of linguistic representations. Here are three executions of this general strategy in recent published work. ${ }^{4}$ First, according to an article by Joshua Seachris in the present issue of this journal, asking about life's meaning is at bottom a matter of enquiring into whether and how a life is understood within a wider frame of reference. He remarks,

I am strongly inclined to think that it is a single question, the asking of which reveals our desire to make sense of life and existence. We want to fit it all together. The foci of this sense-making activity, no doubt, include purpose and significance, but it is the sense-making framework itself-what makes sense of these and other existentially weighty matters-that is the meaning of life (Seachris, 2019, p. 375, emphasis in original).

By this approach, fulfilling a purpose or making a significant difference to the world logically cannot be what bears meaning, which is instead necessarily a sense-making framework, roughly, a narrative interpretation of a certain kind.

Similarly, Thomas in another essay maintains, of what is involved in asking about life's meaning, that,

the traditional question is simply a request for the information which constitutes a coherent answer to one or more of a certain set of questions regarding human existence that were salient to the asker....This analysis can then also be applied to individual lives, such that asking for the meaning of X's life is an analogous request for the information necessary to make sense of that life in particular (Thomas, 2019, p. 1).

Again, it is not an action or even a life, strictly speaking, that can be meaningful or not, by this analysis. Instead, insofar as the sense of the question of life's meaning is no more than a request for information, meaning by definition can be only a certain kind of information, specifically, for Thomas (2019), an explanation of various existential matters concerning what has caused us to exist, what effects we have had on others, what aims we have sought to realize, what the story of our lives has been, and what our lives symbolically represent.

For a third, somewhat distinct analysis of the question of life's meaning in purely cognitive terms, there is the proposal, from Charles Repp (2018), that when we enquire into life's meaning, we are asking about the extent to which, and respects in which, an individual has "perceived sign meaning" (Repp, 2018, p. 404). Sign meaning is what properties signify,

\footnotetext{
4 For a fourth, see Willison (2017). For precursors among philosophers, see talk of "coherence" and "interpretation" in Markus (2003) and Thomson (2003, pp. 8-13), neither of whom took the cognitive to exhaust the conceptual bearer of life's meaning.
} 
e.g., smoke means fire and a frown means sadness. In the way that Sherlock Holmes solves crimes by excelling at detecting signs, that is, drawing inferences from elements of his environment, so one lives meaningfully, perhaps by definition, ${ }^{5}$ insofar as one engages in such an epistemic practice. For example, a religious theory of life's meaning would be that it is constituted by interpreting natural properties as revealing supernatural phenomena, while an aesthetic approach to life's meaning would involve conveying the significance of an event, such as war, in the form of a painting, or perhaps drawing out the significance of a painting for some facet of human life such as war (Repp, 2018, pp. 414, 415, 417).

In addition to noting similarities between "meaning"-talk in the spheres of language and in the realm of life, Seachris, Thomas, and Repp draw on psychological studies and theories to support their analyses. In particular, it is true that a large number of psychologists have thought of meaningfulness (at least partially, and sometimes exhaustively) in terms of having a coherent belief system that "provides us with information about the presence of reliable patterns in the environment" (Martela \& Steger, 2016, p. 533; for just a few others in psychology, see, e.g., Baumeister \& Vohs, 2002; Heintzelman \& King, 2014; Hermans, 1989).

While these considerations merit engagement, what I instead offer here are reasons to doubt the broad position they are meant to support, viz., that it is an analytic truth that thinking about life's meaning is merely a matter of making sense, providing information, or perceiving signs. I am inclined to think that part of what many of us have in mind when thinking about life's meaning is something cognitive (or epistemic), such as telling a good story about it or seeing how its parts fit into a broader context, but I deny that such should be deemed exhaustive of that thinking, for three reasons.

First, while there are those in the field who conceptually identify meaningfulness with intelligibleness, there is conversely a comparably large tradition that thinks of it as ineffability (recently, Bennett-Hunter, 2014; Cooper, 2016; Hosseini, 2015, pp. 13-23; Perrett, 2010; Waghorn, 2014). The ineffable is what cannot be communicated or even conceptualized, and some thinkers have maintained that the ultimate source of meaning in our lives is, and perhaps even must be, grounded on what is ineffable. One rationale for this view has been that meaning is invariably relational, such that a given meaningful condition in a human life must obtain its meaning from another meaningful condition, which, in turn, must obtain its meaning from yet another meaningful condition and so on, until the regress is terminated in something that transcends human life altogether and is essentially unintelligible to us. Insofar as ineffability is one popular, substantive answer to the question of life's meaning, this question should not be understood as essentially asking for what is not ineffable.

Second, analyzing the question of life's meaning in respect of an individual solely in terms of whether, and, if so, how an agent understands her life entails that no meaning is possible for an individual who is dead or otherwise unable to interpret any longer. However, it is widely held that posthumous meaning is possible, with Shakespeare being one promising example. Meaning accrued to Shakespeare's life long after he stopped processing

\footnotetext{
5 I am not sure whether this is meant to be an analysis of the concept of life's meaning common to an array of competing conceptions or a specific conception (cf. Repp, 2018, p. 413).
} 
information about it, in virtue of the positive influence of his writings. One might reply that others have made sense of Shakespeare's life after he died, but, now, suppose that no one had done so in the relevant sense. Imagine that someone other than Shakespeare had in fact written the poems and plays attributed to him; then others would not have been making sense of the actual author's life-but that person's life intuitively would have been meaningful all the same, again because of how many people have been affected by his writings (even if it would have been more meaningful had he been properly recognized for them).

Third, the cognitive (epistemic) analyses of the concept of life's meaning cannot capture the respects in which choices often really do seem to bear meaningfulness. Suppose that you hear a child screaming in a house that is on fire, and you risk your life to rescue the child, with success. I presume we all agree that there is meaning here, or at the very least that it is logically possible that there is meaning here. Now, what could in principle constitute the meaningfulness? It is not so much (or at least not necessarily) that you have inferred from the screams that there is a child in danger (as per Repp), but rather that you acted on such information. It is not so much (or at least not necessarily) that you have fitted this action into a narrative about your life more broadly (Seachris), because you might not have; suppose, for instance, that you have acted out of character on this occasion, or that your discriminatory society does not value heroic rescues of children of this ethnic group. And it is not so much (or at least not necessarily) that you have given an account of the effects of your action or of what your aims were (Thomas), for it is plausibly the effects of the action and the aims behind it themselves that matter, and you might not have bothered to reflect on them either during the rescue or afterward. In short, it is logically consistent to suppose that actions can exhibit meaning, but the purely cognitive analyses of the concept of life's meaning are too narrow for ruling out that possibility.

\section{Human choices beyond final value?}

There is a third major respect in which the standard view has been questioned, which merits consideration independent of the previous two suggested revisions. That is, supposing we are focusing on human lives and then centrally the choices made in them, there has been the recent suggestion that they could be meaningful without being finally valuable, intrinsically desirable, or otherwise positive.

Indeed, most of the revisionists discussed above reject the idea that talk of "life's meaning" connotes something to be valued as an end. De Muijnck remarks of his account that "significance as I have defined it can be negative as well as positive in character: I intend the presents I buy to be significant to my loved one, but jihadists also intend the ravages they cause to be significant to the infidels" (2013, p. 1303). Tartaglia remarks of us and our universe having been created for a purpose: "If reality is meaningful, then the meaning of human life might be good, bad, or neither [...] If life has a meaning, then, this could be bad" (2015, pp. 5, 6). Mawson remarks that some kinds of meaningfulness are "undesirable" (2016, p. 90) and "are not valuable in themselves" (2016, p. 193). Thomas posits that "there can exist other kinds of genuine meaning besides those which we humans happen to find desirable....(W)hen we discuss the meaningfulness of a human life, we are usually intending to evaluate how good it was in some sense, but that does not mean that 
meaningfulness could not be ascribed elsewhere in non-evaluative ways" (2018, pp. 291, 294). ${ }^{6}$

I do not deny the coherence and even advisability of using the word "meaning" (and cognate terms) to describe or explain rather than prescribe or evaluate, and, further, using it to characterize facets of the natural world beyond human lives, such as gravity and sandwiches. However, describing and explaining are markedly distinct from prescribing and evaluating, which distinction recommends separating the two kinds of talk.

After all, the fields of metaphysics and philosophical anthropology are sensibly distinct from ethics and value theory, such that what is meant by, for instance, "human nature" in the former fields could reasonably differ from what the phrase means in the latter ones. By analogy, the phrase "life's meaning" should probably be split up, such that one definition is value neutral and another is taken to include final value. Such a division would help keep the different types of philosophical work being done clear, and would help enable enquirers to avoid speaking past one another.

\section{Conclusion}

In sum, there is strong reason to doubt that the philosophical discourse about life's meaning should be changed in the sense of revising our understanding from the past 40 years or so of what "life's meaning" primarily means (or of what the concept of it includes). In another sense, however, I welcome the recent challenges to the standard view of what the phrase means, for they promise to broaden the horizons of enquiry upon being construed in more plausible ways. So, for example, while I am firm in denying that the question of what makes life meaningful is merely asking for a certain kind of sense-making information, I do accept that this is one thing that philosophers and related enquirers are sometimes seeking, as part of an amalgam of ideas. For another example, while I doubt that a non-evaluative sort of meaningfulness should be considered continuous with the evaluative sort that a very large majority of us have in mind when thinking about human lives, it could well be a revealing category in respect of certain kinds of ontology. Roughly, the new approaches are, I submit, sensibly viewed as supplementing the standard view, not as supplanting it.

\section{Acknowledgement}

For comments on a prior draft of this article, I thank Stephen Leach, James Tartaglia and participants in the International Conference on the Meaning of Life held at the University of Haifa in June 2019.

\footnotetext{
6 Cf. Repp (2018, pp. 420-425); Thomas (2019, pp. 19-21). For a quite different way to question the standard view that meaning-talk by definition connotes final value that can come in different degrees between lives, see Morioka (2015).
} 


\section{References}

Baumeister, R., \& Vohs, K. (2002). The pursuit of meaningfulness in life. In C. R. Snyder \& S. J. Lopez (Eds.), Handbook of positive psychology (pp. 608-618). New York: Oxford University Press.

Bennett-Hunter, G. (2014). Ineffability and religious experience. Oxford: Routledge.

Cooper, D. E. (2016). Music, nature and ineffability. Philosophia, 44, 1257-1266.

de Muijnck, W. (2013). The meaning of lives and the meaning of things. Journal of Happiness Studies, 14, 1291-1307.

Heintzelman, S. J., \& King, L. A. (2014). (The feeling of) meaning-as-information. Personality and Social Psychology Review, 18, 153-167.

Hermans, H. (1989). The meaning of life as an organized process. Psychotherapy, 16, 11-22.

Hosseini, R. (2015). Wittgenstein and meaning in life. New York: Palgrave Macmillan.

Kauppinen, A. (2015). Meaningfulness. In G. Fletcher (Ed.), Routledge handbook of the philosophy of well-being (pp. 281-291). New York: Routledge.

Levy, N. (2005). Downshifting and meaning in life. Ratio, 18, 176-189.

Markus, A. (2003). Assessing views of life: A subjective affair? Religious Studies, 39, 125-143.

Martela, F. (2017). Meaningfulness as contribution. Southern Journal of Philosophy, 55, 232-256.

Martela, F., \& Steger, M. F. (2016). The three meanings of meaning in life: Distinguishing coherence, purpose, and significance. The Journal of Positive Psychology, 11, 531-545.

Mawson, T. J. (2016). God and the meanings of life. London: Bloomsbury Publishing.

Metz, T. (2013). Meaning in life: An analytic study. Oxford: Oxford University Press.

Metz, T. (2016). The proper aim of psychotherapy: Subjective well-being, objective goodness, or a meaningful life? In A. Batthyany, P. Russo-Netzer, \& S. Schulenberg (Eds.), Clinical perspectives on meaning (pp. 17-35). New York: Springer.

Morioka, M. (2015). Is meaning in life comparable? In M. Morioka (Ed.), Reconsidering meaning in life (pp. 50-65). Saitama, Japan: Waseda University.

Nozick, R. (1981). Philosophical explanations. Cambridge, MA: Harvard University Press.

Nozick, R. (1989). The examined life. New York: Simon and Schuster.

Perrett, R. (2010). Ineffability, signification and the meaning of life. Philosophical Papers, 39, 239-255.

Purves, D., \& Delon, N. (2018). Meaning in the lives of humans and other animals. Philosophical Studies, 175, 317-338.

Repp, C. (2018). Life meaning and sign meaning. Philosophical Papers, 47, 403-427.

Seachris, J. (2013). General introduction. In J. Seachris (Ed.), Exploring the meaning of life: An anthology and guide (pp. 1-20). Malden, MA: Wiley-Blackwell.

Seachris, J. (2019). From the meaning triad to meaning holism: Unifying life's meaning. Human Affairs, 29(4), 363-378.

Tartaglia, J. (2015). Philosophy in a meaningless life. London: Bloomsbury.

Thomas, J. L. (2018). Can only human lives be meaningful? Philosophical Papers, 47, 265-297.

Thomas, J. L. (2019). Meaningfulness as sensefulness. Philosophia. https://doi.org/10.1007/s11406-01900063-x

Thomson, G. (2003). On the meaning of life. Melbourne: Wadsworth.

Trisel, B. A. (2007). Judging life and its value. Sorites, 18, 60-75.

Visak, T. (2017). Understanding "meaning of life" in terms of reasons for action. Journal of Value Inquiry, 51, 507-530.

Waghorn, N. (2014). Nothingness and the meaning of life. London: Bloomsbury.

Willison, R. (2017). The ethics of meaning. Doctoral thesis. University of Pennsylvania.

Wolf, S. (2016). Meaningfulness: A third dimension of the good life. Foundations of Science, 21, 253269. 
Wong, W-H. (2008). Meaningfulness and identities. Ethical Theory and Moral Practice, 11, 123-148.

Philosophy Department

B-Ring 7

University of Johannesburg

PO Box 524

Auckland Park

2006

South Africa

Email: tmetz@uj.ac.za 